\title{
Mobilisation of endothelial progenitor cells: one of the possible mechanisms involved in the chronic administration of melatonin preventing erectile dysfunction in diabetic rats
}

\begin{abstract}
Xue-Feng Qiu ${ }^{1}$, Xiao-Xin Li $^{1,2}$, Yun Chen ${ }^{1}$, Hao-Cheng Lin ${ }^{1}$, Wen Yu${ }^{1}$, Run Wang ${ }^{3}$ and Yu-Tian Dai ${ }^{1}$
Diabetes-induced oxidative stress plays a critical role in the mobilisation of endothelial progenitor cells (EPCs) from the bone marrow to the circulation. This study was designed to explore the effects of chronic melatonin administration on the promotion of the mobilisation of EPCs and on the preservation of erectile function in type I diabetic rats. Melatonin was administered to streptozotocin-induced type I diabetic rats. EPCs levels were determined using flow cytometry. Oxidative stress in the bone marrow was indicated by the levels of superoxide dismutase and malondialdehyde. Erectile function was evaluated by measuring the intracavernous pressure during an electrostimulation of the cavernous nerve. The density of the endothelium and the proportions of smooth muscle and collagen in the corpus cavernosum were determined by immunohistochemistry. The administration of melatonin increased the superoxide dismutase level and decreased the malondialdehyde level in the bone marrow. This effect was accompanied by an increased level of circulating EPCs in the diabetic rats. The intracavernous pressure to mean arterial pressure ratio of the rats in the treatment group was significantly greater, compared with diabetic control rats. The histological analysis demonstrated an increase in the endothelial density of the corpus cavernosum after the administration of melatonin. However, melatonin treatment did not change the proportions of smooth muscle and collagen in the corpus cavernosum of diabetic rats. Chronic administration of melatonin has a beneficial effect on preventing erectile dysfunction (ED) in type I diabetic rats. Promoting the mobilisation of EPCs is one of the possible mechanisms involved in the improvement of ED.
\end{abstract}

Asian Journal of Andrology (2012) 14, 481-486; doi:10.1038/aja.2011.161; published online 27 February 2012

Keywords: diabetes; endothelial progenitor cells; erectile dysfunction; melatonin; mobilisation; oxidative stress

\section{INTRODUCTION}

Epidemiological studies have revealed that up to $75 \%$ of men with diabetes suffer from erectile dysfunction (ED). ${ }^{1,2}$ The prevalence of ED has been reported to be higher in men with diabetes compared with non-diabetic men. ${ }^{3-6}$ Furthermore, ED occurs earlier in diabetic men with poor responses to phosphodiesterase- 5 inhibitors, which are considered to be the first-line therapy for ED. ${ }^{7}$

The aetiology of diabetes-associated ED is multifactorial and involves vasculopathy, neuropathy and local pathological processes. ${ }^{8,9}$ Increased levels of oxygen free radicals are thought to be involved in hyperglycaemia-induced tissue damage. ${ }^{10}$ Several antioxidants, such as vitamin E, sodium selenate, melatonin and ascorbic acid, have been demonstrated to reverse ED partially in experimental type I and type II diabetic animals. ${ }^{10}$

Endothelial progenitor cells (EPCs) have been shown in both animal models and in humans to contribute to neovascularisation and reendothelialisation, indicating an essential role for these progenitor cells in maintaining endothelial integrity. ${ }^{1-13}$ Recently, a growing number of studies have reported an inverse correlation between the number of EPCs and subjects' erectile function, suggesting a possible role for the reduction of EPCs in the development of ED. ${ }^{14-17}$

EPCs appear to be affected by clinical conditions characterized by high cardiovascular risks, including type I and type II diabetes. Moreover, the number of circulating EPCs is decreased in subjects with diabetes. ${ }^{18-21}$ Increasing evidence suggests that oxidative stress, which is involved in the pathogenesis of diabetes, plays a crucial role in mediating the mobilisation of EPCs from the bone marrow to the peripheral circulation, both in experimental animal models and in humans. $^{22,23}$

Melatonin is a powerful antioxidant. Numerous studies have suggested a role for melatonin in reducing the oxidative stress induced in many organs by diabetes. ${ }^{24,25}$ Our study, therefore, was designed to explore the effect of melatonin in decreasing oxidative stress induced by type I diabetes and in promoting the mobilisation of EPCs. Our 
hypothesis was that the chronic administration of melatonin would reduce oxidative stress levels, improve mobilisation of EPCs and subsequently prevent $\mathrm{ED}$ in diabetic rats.

\section{MATERIALS AND METHODS}

\section{Animal groups and study design}

All animal procedures were approved by the Institutional Animal Care and Use Committee at Nanjing University (Nanjing, China). Streptozotocin-induced type I diabetic rats were randomly divided into a melatonin-treated group ( $\mathrm{Mt}, n=11)$ and a diabetic control group (DM, $n=11)$. Melatonin $\left(10 \mathrm{mg} \mathrm{kg}^{-1} \mathrm{day}^{-1}\right.$, intraperitoneal $\left.{ }^{26}\right)$ or saline was administered to the melatonin-treated group or diabetic control group. Saline was administered to the normal control rats $(\mathrm{N}, n=10)$. Treatment was continued for 8 weeks, followed by a washout period of $72 \mathrm{~h}$. Melatonin was obtained from Sigma (St. Louis, MO, USA). The peripheral blood of every rat was harvested for flow cytometry before erectile function was measured. Penile tissue and bone marrow were harvested for the analysis after assessing erectile function.

\section{Establishment of the diabetic model}

Thirty-six male Sprague-Dawley rats (10 weeks old) were used in this study. After an overnight fast, 26 rats were intraperitoneally injected with streptozotocin $\left(60 \mathrm{mg} \mathrm{kg}^{-1}\right.$; Sigma) dissolved in a citrate acid buffer solution. The remaining 10 rats were injected with an equivalent volume of citrate buffer solution, and they served as normal controls. Blood glucose levels were measured $72 \mathrm{~h}$ later. Rats that had a blood glucose level higher than $200 \mathrm{mg} \mathrm{dl}^{-1}$ were selected as type I diabetic rats. $^{27}$

\section{Flow cytometry analysis}

The number of EPCs in the circulation was determined by $\mathrm{CD}^{+} 4^{+}$, kinase insert domain receptor ${ }^{+}\left(\mathrm{KDR}^{+}\right)$cells. $^{14}$ Blood samples were harvested from the angular vein and collected in heparinized tubes. Mononuclear cells in $1 \mathrm{ml}$ of blood were isolated from peripheral blood samples by density centrifugation. Whole mononuclear cells were washed and blocked with $2.5 \%$ bovine serum albumin, subsequently incubated with Alexa-488-conjugated mouse anti-CD34 antibody (Santa Cruz Biotechnology, Santa Cruz, CA, USA; $1: 400$ ) and rabbit anti-KDR primary antibody (Abcam Inc., Cambridge, UK; $1: 400$ ) for $2 \mathrm{~h}$ at room temperature. After washing three times with phosphate-buffered saline (PBS), the cells were resuspended and incubated with Alexa-594-conjugated goat anti-rabbit secondary antibody (Invitrogen, Carlsbad, CA, USA; $1: 200$ ) for $1 \mathrm{~h}$ at room temperature. The cells were finally resuspended in $800 \mu \mathrm{l}$ of PBS and analysed with a FACSCalibur (BD Biosciences, San Jose, CA, USA) flow cytometer. One hundred thousand cells were acquired in each sample, and the percentage of $\mathrm{CD} 34^{+} / \mathrm{KDR}^{+}$cells was determined.

\section{Erectile function evaluation}

The intracavernous pressure (ICP) response to an electrical stimulation of the cavernous nerve was measured as previously described. ${ }^{28}$ After anaesthesia by ketamine $\left(100 \mathrm{mg} \mathrm{kg}^{-1}\right)$ and midazolam $(5 \mathrm{mg}$ $\mathrm{kg}^{-1}$ ), the major pelvic ganglion and cavernous nerve were exposed on either side of the prostate. A 25-gauge needle, connected to a PE-50 tube and filled with $200 \mathrm{U} \mathrm{ml}^{-1}$ heparin, was inserted into the left corpora for the measurement of ICP. The left carotid artery was subsequently exposed and cannulated with a PE-50 tube to record the mean arterial pressure (MAP). The nerve was stimulated at a frequency of $15 \mathrm{~Hz}$ with a pulse width of $5 \mathrm{~ms}$. Stimulations were performed at $5 \mathrm{~V}$ for $60 \mathrm{~s}$ with a period of $5 \mathrm{~min}$ between subsequent stimulations. The ratio of peak ICP to MAP was calculated to evaluate erectile function.

\section{Oxidative stress parameters in bone marrow}

Bone marrow from both femurs was flushed out with $1.5 \mathrm{ml}$ of PBS. After centrifuging at $3000 \mathrm{~g}$ for $10 \mathrm{~min}$, the supernatant was collected and stored at $-80{ }^{\circ} \mathrm{C}$. Levels of superoxide dismutase (SOD) and malondialdehyde (MDA) were used to evaluate oxidative stress levels in the bone marrow. The levels of MDA and SOD in bone marrow were measured using commercially available kits, according to the manufacturer's protocol (Jiancheng Bioengineering Institute, Nanjing, China). SOD levels in the bone marrow were expressed as $\mathrm{U} \mathrm{mg}^{-1}$ of protein, while MDA was expressed as nmol $\mathrm{mg}^{-1}$ of protein.

\section{Histology}

The middle parts of the penile tissues were fixed in $4 \%$ paraformaldehyde in PBS at $4{ }^{\circ} \mathrm{C}$ overnight, followed by transferring them to $30 \%$ sucrose in PBS at $4{ }^{\circ} \mathrm{C}$ overnight. The tissues were embedded at optimal cutting temperature and stored at $-80{ }^{\circ} \mathrm{C}$.

For immunofluorescence staining, the sections were blocked by incubation in $2.5 \%$ bovine serum albumin for $30 \mathrm{~min}$ at room temperature. Penile sections were then incubated with rabbit anti-von Willebrand factor (vWF; Abcam Inc.; $1: 400$ ) and mouse anti $\alpha$ smooth muscle actin ( $\alpha$-SMA, Abcam Inc., $1: 400)$ overnight at $4{ }^{\circ} \mathrm{C}$, followed by Alexa-488- or Alexa-594-conjugated secondary antibodies (Invitrogen; $1: 200$ ) for $1 \mathrm{~h}$ at room temperature. Masson's Trichrome staining was performed using a commercial available kit (Sigma), according to the manufacturer's instructions.

A digital histomorphometric analysis was performed using ImagePro Plus 6.0 software (Media Cybernetics, Silver Spring, MD, USA). For vWF staining, the corpus cavernosum was examined at $\times 100$ magnification, and the proportions of vWF-positive area and total corpus cavernosum area were calculated. To determine the endothelium content in the dorsal artery, $\times 400$-magnification images were examined, and the ratio of vWF-positive endothelium to $\alpha$-SMApositive smooth muscle in the dorsal artery was used for a quantitative analysis. To determine the ratio of smooth muscle to collagen within the corpus cavernosum, the $\times 100$-magnification of Masson's trichrome staining was analysed. Five sections from each sample were examined for a quantitative analysis.

\section{Statistical analysis}

The results were expressed as the mean \pm s.d., and the data were analysed by a one-way analysis of variance to compare among multiple groups, followed by post hoc comparisons with the least significant difference test. $P<0.05$ was considered statistically significant.

\section{RESULTS}

\section{General data}

Among the 26 rats injected with streptozotocin, 22 rats with blood glucose greater than $200 \mathrm{mg} \mathrm{dl}^{-1}$ were selected as diabetic rats. As shown in Table 1, the body weights of the diabetic rats in group $\mathrm{DM}$ and group Mt were lower than the normal rats 8 weeks after the streptozotocin injection $(P<0.01)$. Blood glucose levels of the diabetic rats in group DM and group Mt were higher than the normal rats $(P<0.01)$ (Table 1). Chronic administration of melatonin did not increase body weight or decrease blood glucose (Table 1). 
Table 1 Comparison of body weight and blood glucose between each experimental group (mean \pm s.d.)

\begin{tabular}{lcrlcl}
\hline \multirow{2}{*}{ Groups } & \multicolumn{2}{c}{ Initial } & & \multicolumn{2}{c}{8 weeks } \\
\cline { 2 - 3 } \cline { 5 - 6 } & \multicolumn{1}{c}{$B W(g)$} & $B G\left(m g d l^{-1}\right)$ & & $B W(g)$ & $B G\left(m g d l^{-1}\right)$ \\
\hline $\mathrm{N}$ & $202.5 \pm 13.1$ & $99.4 \pm 12.7$ & & $488.8 \pm 56.5$ & $102.3 \pm 12.4$ \\
$\mathrm{DM}$ & $196.7 \pm 15.8$ & $101.8 \pm 13.1$ & & $258.2 \pm 43.4^{*}$ & $474.6 \pm 58.7^{*}$ \\
$\mathrm{Mt}$ & $198.8 \pm 11.8$ & $102.8 \pm 14.2$ & & $253.9 \pm 39.7^{*}$ & $472.8 \pm 64.8^{*}$ \\
\hline
\end{tabular}

Abbreviations: BG, blood glucose; BW, body weight; DM, diabetic group; Mt, melatonin treatment group; $\mathrm{N}$, normal group.

$* P<0.01$ compared with $\mathrm{N}$ group (one-way analysis of variance with post-testing was used to assess statistical significance).

\section{Melatonin administration increased $\mathrm{CD} 34^{+} / \mathrm{KDR}^{+} \mathrm{EPCs}$ in peripheral blood}

As shown in Figure 1, the percentage of $\mathrm{CD} 34^{+} / \mathrm{KDR}^{+}$cells in the peripheral blood of the diabetic rats was lower than the normal controls $(P<0.05)$. Chronic administration of melatonin increased the percentage of CD34 ${ }^{+} / \mathrm{KDR}^{+}$EPCs in peripheral blood compared with the diabetic controls $(P<0.05)$.

\section{Melatonin improved erectile function}

The effect of chronic administration of melatonin on improving erectile function is shown in Figure 2. The development of ED in diabetic rats was demonstrated by a lower ICP/MAP ratio in the diabetic control group compared with the normal controls $(P<0.05)$. A partial but significant improvement of erectile function was observed in the melatonin-treated group.

Oxidative stress levels in bone marrow decreased after melatonin administration

Oxidative stress in the bone marrow was indicated by a decreased SOD level and an increased MDA level in the diabetic controls compared with the normal controls $(P<0.05)$ (Table 2$)$. The administration of melatonin increased SOD levels and decreased MDA levels in the bone marrow compared with the diabetic control group $(P<0.05)$ (Table 2).

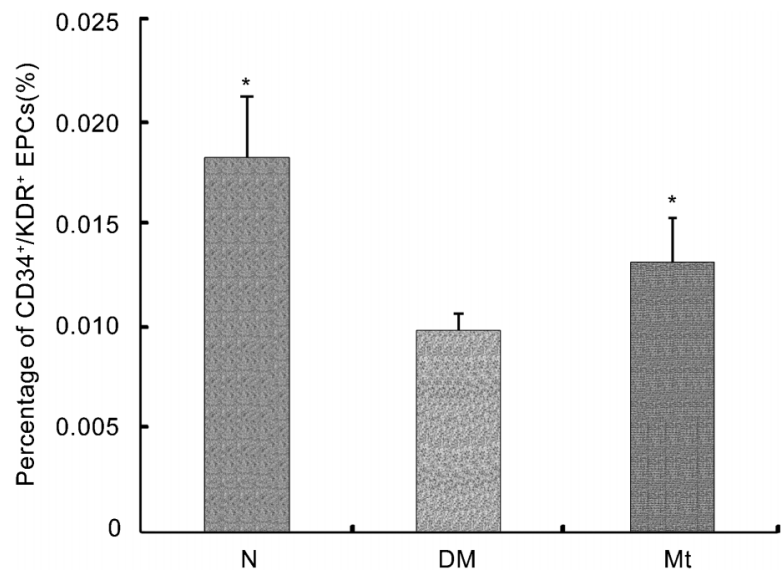

Figure $1 \mathrm{CD}^{+} 4^{+} / \mathrm{KDR}^{+}$endothelial progenitor cells (EPCs) in circulation. The level of $\mathrm{CD}_{3} 4^{+} / \mathrm{KDR}^{+}$cells in peripheral blood was expressed as percentage of $\mathrm{CD}_{3} 4^{+} / \mathrm{KDR}^{+}$cells in mononuclear cells. $* P<0.05$ compared with the diabetic group. DM, diabetic group; Mt, melatonin treatment group; N, normal group.

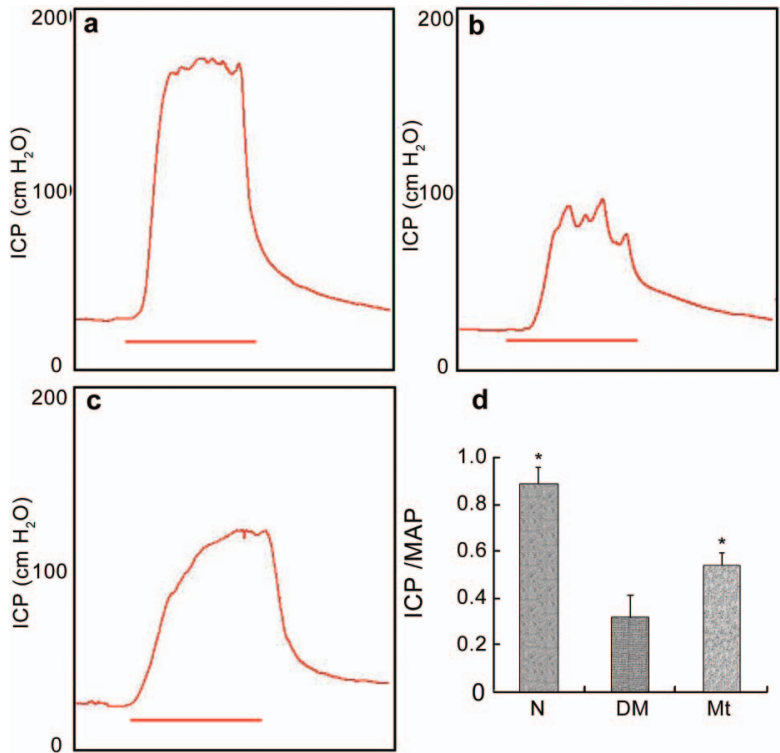

Figure 2 Erectile function evaluation. (a-c) Representative images of intracavernous pressure (ICP) responding to stimulation of the cavernous nerve of each experimental group: (a) normal group; (b) diabetic group; (c) melatonin treatment group. Red bars represent 60-s electronic stimulation. (d) Results of erectile function expressed as the ratio between ICP and mean arterial pressure (MAP). ${ }^{*} P<0.05$ compared with the diabetic group. DM, diabetic group; Mt, melatonin treatment group, $\mathrm{N}$, normal group.

Endothelium density increased after melatonin administration Consistent with our previous study, ${ }^{28}$ the endothelial density in the corpus cavernosum of the diabetic rats decreased compared with the normal rats $(P<0.05)$. Endothelial content was higher than in the diabetic control group after 8 weeks of melatonin administration $(P<0.05)$. Chronic treatment with melatonin resulted in partial restoration of the endothelium in the corpus cavernosum (Figure 3).

\section{Effect of melatonin on the smooth muscle/collagen ratio in the} corpus cavernosum

As shown in Figure 4, the ratio of smooth muscle to collagen was reduced $(P<0.05)$ in the corpus cavernosum of diabetic controls compared with normal controls. However, histological data revealed that the chronic administration of melatonin did not alter this decreased smooth muscle/collagen ratio in the corpus cavernosum.

\section{DISCUSSION}

Recent studies have suggested that EPCs play a major role in the regeneration of the endothelial monolayer, as well as in neoangiogenesis. ${ }^{12}$ These cells have the capacity to migrate from the bone marrow into the peripheral circulation in response to tissue ischemia or traumatic injury,

Table 2 Comparison of oxidative stress parameters in bone marrow between each experimental group

\begin{tabular}{lcc}
\hline Groups & SOD $\left(U \mathrm{mg}^{-1}\right.$ protein $)$ & $M D A\left(\mathrm{nmol} \mathrm{mg}^{-1}\right.$ protein $)$ \\
\hline $\mathrm{N}$ & $102.57 \pm 10.96 *$ & $4.76 \pm 0.72 *$ \\
$\mathrm{DM}$ & $65.48 \pm 8.13$ & $9.60 \pm 0.92$ \\
$\mathrm{Mt}$ & $90.26 \pm 9.46^{*}$ & $7.33 \pm 0.88^{*}$ \\
\hline
\end{tabular}

Abbreviations: DM, diabetic group; MDA, malondialdehyde; Mt, melatonin treatment group; N, normal group; SOD, superoxide dismutase.

$* P<0.05$ compared with DM group (one-way analysis of variance with post testing was used to assess statistical significance). 

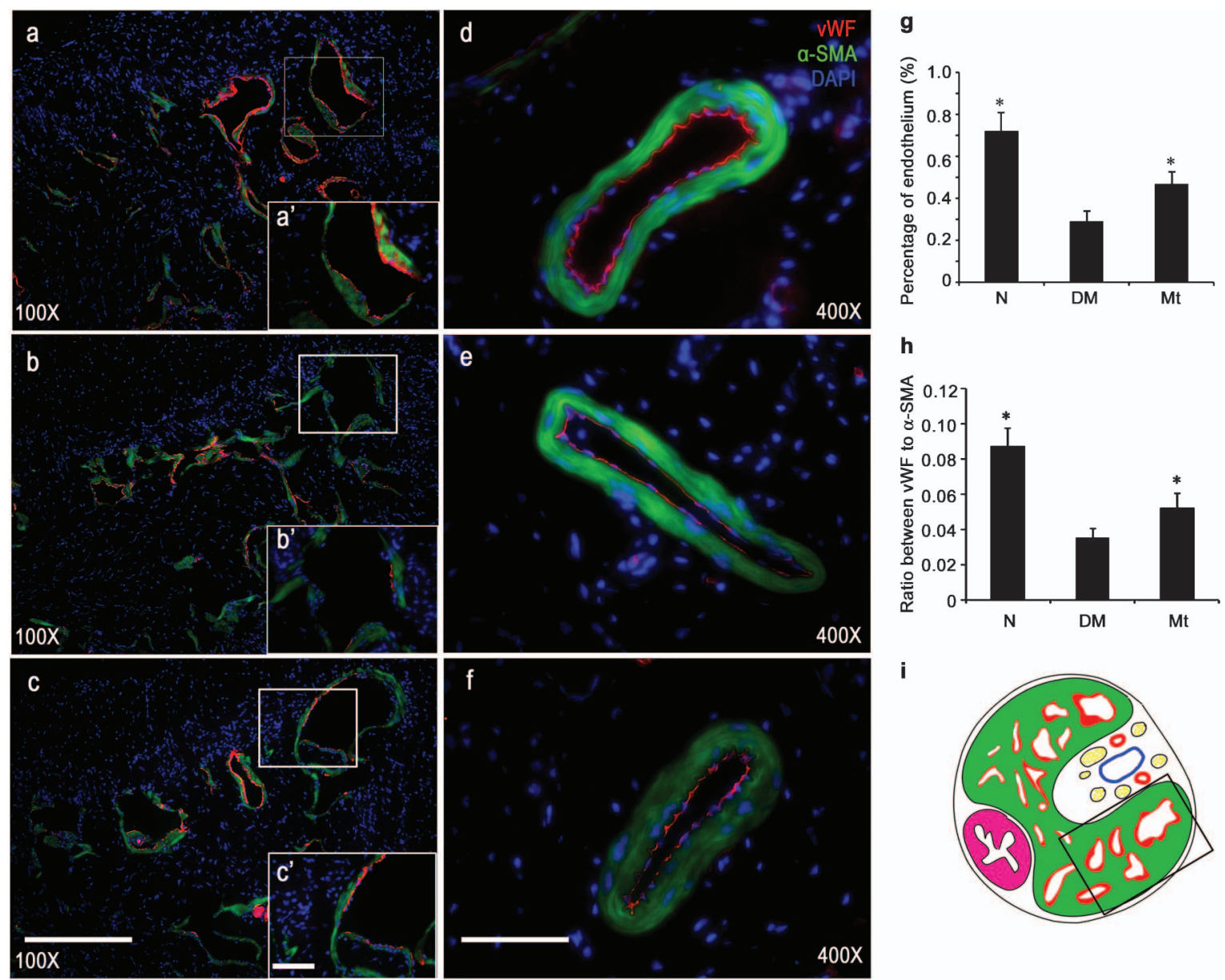

Figure 3 Endothelium density in the corpuscavernosum. (a-c) Representative images of endothelium in the corpus cavernosum of each experimental group: (a) normal group; (b) diabetic group; (c) melatonin treatment group. Original magnification is $\times 100$. Scare bar $=200 \mu \mathrm{m}$. High magnifications of the boxed area in $\left(\mathbf{a}^{\prime}-\mathbf{c}^{\prime}\right)$ further show the anti-von Willebrand factor (VWF) expression in corpus cavernosum. Original magnification is $\times 400$. Scare bar $=50 \mu \mathrm{m}$. (d-f) Representative images of endothelium in dorsal artery of each group: (d) normal group; (e) diabetic group; (f) melatonin treatment group. Original magnification is $\times 400$. Scar bar $=50 \mu \mathrm{m}$. (g) Results of the endothelium quantification expressed as the ratio of vWF-positive endothelium to in the corpus cavernosum. (h) Results of the endothelium quantification expressed as the ration of vWF-positive endothelium to the $\alpha$-SMA-positive smooth muscle in dorsal artery. (i) The field in the boxed area was used for quantitative analysis. ${ }^{\#} P<0.05$ compared with the diabetic group. $\alpha$-SMA, $\alpha$-smooth muscle actin.

as well as the ability to differentiate into mature endothelial cells in situ. It has been demonstrated, both in animal models and in humans, that the beneficial effects of EPCs for neovascularisation and re-endothelialisation are also mediated through the paracrine secretion of angiogenic factors. $^{12}$

EPC levels are decreased in patients with cardiovascular disease or with cardiovascular risk factors. ${ }^{29,30}$ Furthermore, healthy subjects with endothelial dysfunction have a decreased number of circulating EPCs. ${ }^{11}$ Circulating levels of EPCs are thought to be a pathophysiological link between cardiovascular risk factors and endothelial dysfunction. ${ }^{29,31}$ Erections are mainly neurovascular events, which require intact and functional endothelium and smooth muscle in the corpus cavernosum. Endothelial dysfunction is one of the pathological causes of ED. ED has been suggested to be an early symptom of endothelial dysfunction, and it presents as the first clinical manifestation, as well as a reliable predictor of cardiovascular disease. ${ }^{32}$ Hence, levels of circulating EPCs may indicate an association between cardiovascular risk factors and ED. Foresta et al. ${ }^{15}$ reported that the number of circulating progenitor cells was decreased in ED patients with and without cardiovascular disease. The inverse relationship between the level of circulating EPCs and erectile function was observed in patients with coronary disease, indicating a link between EPCs and ED. ${ }^{17}$ Esposito et al. ${ }^{14}$ demonstrated that EPC levels were decreased in overweight men with $\mathrm{ED}$ and were correlated with the severity of ED. These data verified that the reduction in the level of circulating EPCs was inversely related to erectile function.

A growing amount of data have demonstrated reduced EPCs levels in type I and type II diabetes, which are common risk factors for cardiovascular disease. ${ }^{17,19,20}$ EPC reduction has been hailed as a novel concept in the pathogenesis of diabetic vascular complications. In the present study, flow cytometry data showed that the number of $\mathrm{CD} 4^{+} / \mathrm{KDR}^{+}$EPCs in the peripheral circulation was reduced compared with the normal controls. Upon histological examination, diabetic animals demonstrated a decreased amount of endothelium in the corpus cavernosum. The mobilisation of stem cells or progenitor cells from the bone marrow is dependent on the local activity of endothelial nitric oxide (NO) synthase. ${ }^{33} \mathrm{NO}$, generated by the vascular cells of the bone marrow stroma, acts in a paracrine manner to induce mobilisation of EPCs, thereby increasing the number of these cells in the circulation. ${ }^{34}$ Increasing evidence suggests that oxidative stress plays a crucial role in EPC mobilisation, both in animals and in humans. ${ }^{22}$ Conditions associated with increased oxidative stress 


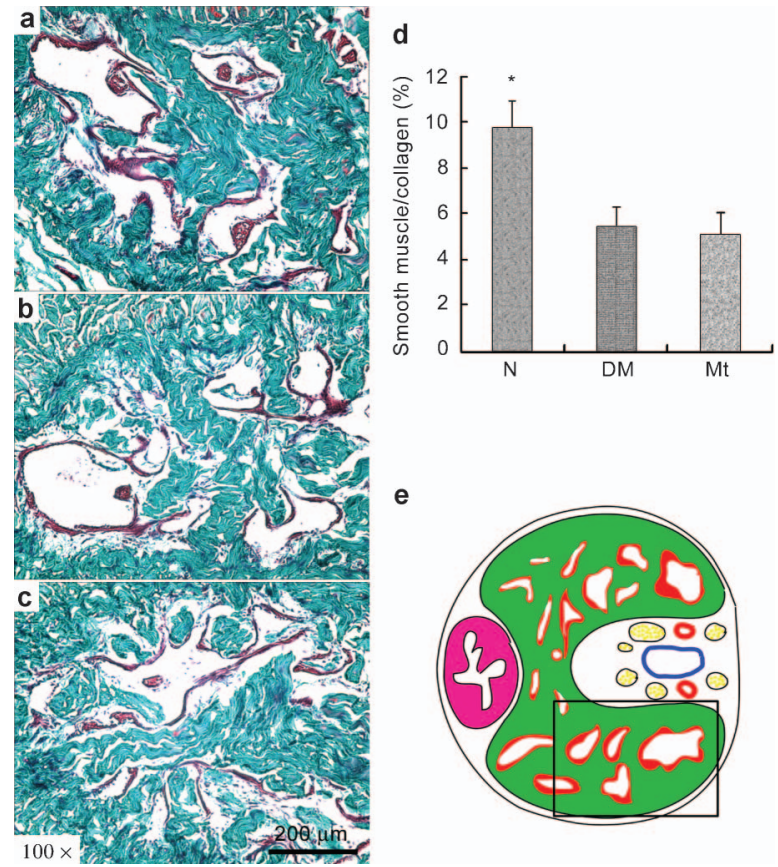

Figure 4 Masson's trichrome staining. (a-c) Representative images of Masson's trichrome staining of each experimental group: (a) normal group; (b) diabetic group; (c) melatonin treatment group. Original magnification is $\times 100$. Scar bar $=200 \mu \mathrm{m}$. (d) Results expressed as the ratio between smooth muscle and collagen in corpus cavernosum. (e) The field in the boxed area was used for quantitative analysis. ${ }^{*} P<0.05$ compared with the diabetic group.

decrease mobilisation and subsequently reduce numbers of circulating EPCs. ${ }^{13}$ Oxidative stress is defined as the situation characterized by increased generation of free radicals (reactive oxygen species), resulting in increased oxidative damage to biological structures The existence of increased oxidative stress in diabetes mellitus has been well documented. ${ }^{24}$ In our study, increased oxidative stress to the bone morrow was indicated by decreased SOD and increased MDA in diabetic rats. Oxidative stress-associated impaired mobilisation of EPCs from the bone marrow to the peripheral circulation may be a possible explanation for the decreased level of EPCs in diabetes.

Melatonin, which is primarily released by the pineal gland, was recently found to be a potent antioxidant and free radical scavenger. ${ }^{35,36}$ Possible mechanisms include the formation of a radical adduct by transferring a hydrogen atom and a single electron. ${ }^{37}$ Additionally, melatonin acts as an indirect antioxidant through the activation of major antioxidant enzymes, including SOD. ${ }^{38}$ Melatonin protects tissues against the oxidant damage induced by various free radical-generating processes. ${ }^{28-30}$ The anti-oxidative effect of melatonin is systemic. Evidence suggests a role for melatonin in reducing the oxidative stress induced in many organs by diabetes. ${ }^{24,25}$ Our study demonstrated the antioxidant property of melatonin in the bone marrow. The chronic administration of melatonin reduced oxidative stress levels in the bone marrow of diabetic rats. Attenuated oxidative stress in bone marrow is one of the possible mechanisms involved in increased EPC mobilisation in melatonin-treated diabetic rats, because of the role of oxidative stress in mediating EPC mobilisation. Melatonin-treated diabetic rats displayed increased amounts of endothelium in the corpus cavernosum and better erectile function. Increased circulating EPC levels are one of the possible explanations for preserved histological and functional change based on the role of EPCs in endothelial regeneration and the development of ED. In addition to enhancing the mobilisation of EPCs from the bone marrow, melatonin may have the beneficial effect of increasing NO availability and preserving the NO/cGMP pathway in penile tissue. ${ }^{39}$ Moreover, the local anti-oxidative effect of melatonin in the corpus cavernosum may contribute to improved histological and functional changes because several antioxidants have been reported to be effective for ED in animals. ${ }^{40-42}$ Furthermore, melatonin has a smooth muscle relaxant effect on the corpus cavernosum of diabetic rats. ${ }^{43}$

This study does have some limitations. First, the animal models used in this study had type I diabetes, which has a lower prevalence in the population than type II diabetes. Furthermore, type I diabetic animal models have different characteristics than rats with type II diabetes, including differences in insulin resistance and in body mass index. Second, this study lacked a non-diabetic group treated with chronic melatonin administration. Further studies will be undertaken to explore the impact of melatonin treatment on normal rats.

\section{CONCLUSION}

The chronic administration of melatonin, an antioxidant, attenuated oxidative stress in the bone marrow, increased circulating EPC levels and subsequently preserved erectile function and corporal histology in diabetic rats. The potential effect of antioxidants on improving the mobilisation of EPCs could provide an alternative opportunity for the treatment of diabetes-associated ED or cardiovascular disease in humans.

\section{AUTHOR CONTRIBUTIONS}

$\mathrm{XFQ}, \mathrm{XXL}, \mathrm{WY}$ and HCL carried out the molecular genetic studies, participated in the sequence alignment and drafted the manuscript. XFQ and XXL carried out the immunoassays. XFQ and YC participated in the design of the study and performed the statistical analysis. RW and YTD conceived of the study, participated in its design and coordination and helped to draft the manuscript. All authors read and approved the final manuscript.

\section{COMPETING FINANCIAL INTERESTS}

The authors declare no competing financial interests.

\section{ACKNOWLEDGMENTS}

This study was supported by the National Natural Science Foundation of China (no. 30800546) and by a grant from the China Scholarship Council (no. 20099619079).

1 Teles AG, Carreira M, Alarcao V, Sociol D, Aragues JM et al. Prevalence, severity, and risk factors for erectile dysfunction in a representative sample of 3,548 Portuguese men aged 40 to 69 years attending primary healthcare centers: results of the Portuguese erectile dysfunction study. J Sex Med 2008; 5: 1317-24.

2 Yang G, Pan C, Lu J. Prevalence of erectile dysfunction among Chinese men with type 2 diabetes mellitus. Int J Impot Res 2010; 22: 310-7.

3 Giuliano FA, Leriche A, Jaudinot EO, de Gendre AS. Prevalence of erectile dysfunction among 7689 patients with diabetes or hypertension, or both. Urology 2004; 64 1196-201.

4 de Berardis G, Franciosi M, Belfiglio M, Di Nardo B, Greenfield S et al. Erectile dysfunction and quality of life in type 2 diabetic patients: a serious problem too often overlooked. Diabetes Care 2002; 25: 284-91.

5 Cho NH, Ahn CW, Park JY, Ahn TY, Lee HW et al. Prevalence of erectile dysfunction in Korean men with type 2 diabetes mellitus. Diabet Med 2006; 23: 198-203.

6 Feldman HA, Goldstein I, Hatzichristou DG, Krane RJ, McKinlay JB. Impotence and its medical and psychosocial correlates: results of the Massachusetts Male Aging Study. J Urol 1994; 151: 54-61. 
7 Dorsey P, Keel C, Klavens M, Hellstrom WJ. Phosphodiesterase type 5 (PDE5) inhibitors for the treatment of erectile dysfunction. Expert Opin Pharmacother 2010; 11: 1109-22.

8 Malavige LS, Levy JC. Erectile dysfunction in diabetes mellitus. J Sex Med 2009; 6: 1232-47.

9 Moore CR, Wang R. Pathophysiology and treatment of diabetic erectile dysfunction. Asian J Androl 2006; 8: 675-84.

10 Gur S, Kadowitz PJ, Hellstrom WJ. A critical appraisal of erectile function in animal models of diabetes mellitus. Int J Androl 2009; 32: 93-114.

11 Dimmeler S, Zeiher AM. Vascular repair by circulating endothelial progenitor cells: the missing link in atherosclerosis? J Mol Med (Berl) 2004; 82: 671-7.

12 Urbich C, Dimmeler S. Endothelial progenitor cells - characterization and role in vascular biology. Circ Res 2004; 95: 343-53.

13 Tousoulis D, Andreou I, Antoniades C, Tentolouris C, Stefanadis C. Role of inflammation and oxidative stress in endothelial progenitor cell function and mobilization: therapeutic implications for cardiovascular diseases. Atherosclerosis 2008; 201: 236-47.

14 Esposito K, Ciotola M, Maiorino MI, Giugliano F, Autorino R et al. Circulating $\mathrm{CD} 34^{+} \mathrm{KDR}^{+}$endothelial progenitor cells correlate with erectile function and endothelial function in overweight men. J Sex Med 2009; 6: 107-14.

15 Foresta C, Caretta N, Lana A, Cabrelle A, Palu G et al. Circulating endothelial progenitor cells in subjects with erectile dysfunction. Int J Impot Res 2005; 17: 288-90.

16 Foresta C, Ferlin A, de Toni L, Lana A, Vinanzi C et al. Circulating endothelial progenitor cells and endothelial function after chronic Tadalafil treatment in subjects with erectile dysfunction. Int J Impot Res 2006; 18: 484-8.

17 Baumhakel M, Werner N, Bohm M, Nickenig G. Circulating endothelial progenitor cells correlate with erectile function in patients with coronary heart disease. Eur Heart J 2006; 27: 2184-8.

18 Werner N, Nickenig G. Influence of cardiovascular risk factors on endothelial progenitor cells-limitations for therapy? Arterioscler Thromb Vasc Biol 2006; 26: 257-66.

19 Loomans CJ, de Koning EJ, Staal FJ, Rookmaaker MB, Verseyden C et al. Endothelial progenitor cell dysfunction-a novel concept in the pathogenesis of vascular complications of type 1 diabetes. Diabetes 2004; 53: 195-9.

20 Tepper OM, Galiano RD, Capla JM, Kalka C, Gagne PJ et al. Human endothelial progenitor exhibit impaired proliferation, cells from type II diabetics adhesion, and incorporation into vascular structures. Circulation 2002; 106: 2781-6.

21 Fadini GP, Sartore S, Albiero M, Baesso I, Murphy E et al. Number and function of endothelial progenitor cells as a marker of severity for diabetic vasculopathy. Arterioscler Thromb Vasc Biol 2006; 26: 2140-6.

22 Yao EH, Yu Y, Fukuda N. Oxidative stress on progenitor and stem cells in cardiovascular diseases. Curr Pharm Biotechnol 2006; 7: 101-8.

23 Loomans CJ, de Koning EJ, Staal FJ, Rabelink TJ, van Zonneveld AJ. Endothelial progenitor cell dysfunction in type I diabetes: Another consequence of oxidative stress? Antioxid Redox Signal 2005; 7: 1468-75.

24 Aksoy N, Vural H, Sabuncu T, Aksoy S. Effects of melatonin on oxidative-antioxidative status of tissues in streptozotocin-induced diabetic rats. Cell Biochem Funct 2003; 21: 121-5.

25 Winiarska K, Fraczyk T, Malinska D, Drozak J, Bryla J. Melatonin attenuates diabetesinduced oxidative stress in rabbits. J Pineal Res 2006; 40: 168-76.
26 Paskaloglu K, Sener G, Ayanoglu-Dulger G. Melatonin treatment protects against diabetes-induced functional and biochemical changes in rat aorta and corpus cavernosum. Eur J Pharmacol 2004; 499: 345-54

27 Bivalacqua TJ, Usta MF, Kendirci M, Pradhan L, Alvarez X et al. Superoxide anion production in the rat penis impairs erectile function in diabetes: influence of in vivo extracellular superoxide dismutase gene therapy. J Sex Med 2005; 2: 187-97.

28 Qiu X, Lin H, Wang Y, Yu W, Chen Y et al. Intracavernous transplantation of bone marrow-derived mesenchymal stem cells restores erectile function of streptozocininduced diabetic rats. J Sex Med 2011; 8: 427-36.

29 Hill JM, Zalos G, Halcox JP, Schenke WH, Waclawiw MA et al. Circulating endothelial progenitor cells, vascular function, and cardiovascular risk. N Eng/ J Med 2003; 348: 593-600.

30 Werner N, Kosiol S, Schiegl T, Ahlers P, Walenta K et al. Circulating endothelial progenitor cells and cardiovascular outcomes. New Engl J Med 2005; 353: 9991007.

31 Valgimigli M, Rigolin GM, Fucili A, Della Porta M, Soukhomovskaia O et al. CD34 ${ }^{+}$and endothelial progenitor cells in patients with various degrees of congestive heart failure. Circulation 2004; 110: 1209-12

32 Solomon H, Man JW, Jackson G. Erectile dysfunction and the cardiovascular patient: endothelial dysfunction is the common denominator. Heart 2003; 89: 251-4.

33 Aicher A, Heeschen C, Dimmeler S. The role of NOS3 in stem cell mobilization. Trends Mol Med 2004; 10: 421-5.

34 Aicher A, Heeschen C, Mildner-Rihm C, Urbich C, Ihling C et al. Essential role of endothelial nitric oxide synthase for mobilization of stem and progenitor cells. Nat Med 2003; 9: 1370-6.

35 Allegra M, Reiter RJ, Tan DX, Gentile C, Tesoriere L et al. The chemistry of melatonin's interaction with reactive species. J Pineal Res 2003; 34: 1-10.

36 Baydas G, Gursu MF, Yilmaz S, Canpolat S, Yasar A et al. Daily rhythm of glutathione peroxidase activity, lipid peroxidation and glutathione levels in tissues of pinealectomized rats. Neurosci Lett 2002; 323: 195-8.

37 Galano A, Tan DX, Reiter RJ. Melatonin as a natural ally against oxidative stress: a physicochemical examination. J Pineal Res 2011; 51: 1-16.

38 Hardeland R. Antioxidative protection by melatonin-multiplicity of mechanisms from radical detoxification to radical avoidance. Endocrine 2005; 27: 119-30.

39 Angulo J, Peiro C, Cuevas P, Gabancho S, Fernandez A et al. The novel antioxidant, AC3056 (2,6-di-t-butyl-4-((dimethyl-4-methoxyphenylsilyl)methyloxy)phenol), reverses erectile dysfunction in diabetic rats and improves NO-mediated responses in penile tissue from diabetic men. J Sex Med 2009; 6: 373-87.

40 Zhang W, Wang Y, Yang Z, Qiu J, Ma J et al. Antioxidant treatment with quercetin ameliorates erectile dysfunction in streptozotocin-induced diabetic rats. J Biosci Bioeng $2011 ; 112$ : 215-8.

41 Zhang Q, Radisavljevic ZM, Siroky MB, Azadzoi KM. Dietary antioxidants improve arteriogenic erectile dysfunction. Int J Androl 2011; 34: 225-35.

42 Ferrini MG, Moon J, Rivera S, Rajfer J, Gonzalez-Cadavid NF. Amelioration of diabetes-induced cavernosal fibrosis by antioxidant and anti-transforming growth factor-betal therapies in inducible nitric oxide synthase-deficient mice. BJU Int; e-pub ahead of print 18 August 2011; doi:10.1111/j.1464-410X.2011.10397.x.

43 Paskaloglu K, Sener G, Ayangolu-Dulger G. Melatonin treatment protects against diabetes-induced functional and biochemical changes in rat aorta and corpus cavernosum. Eur J Pharmacol 2004; 499: 345-54. 